\title{
Editorial
}

\section{Special Section on Fire Experiments and Buildings}

\author{
Antonio Bilotta* and Emidio Nigro, Department of Structures for Engineering \\ and Architecture, University of Naples Federico II, Naples, Italy
}

The idea of this special section stems from an exchange of knowledge and relevant experience among experts in the field of fire safety at the IFireSS 2017 symposium held in Naples. The keynote speakers (Prof. Venkatesh Kodur, Prof. Luke Bisby, and Prof. Guillermo Rein) noted the progress made in fire engineering in the last few decades, and the increasingly widespread application of the so-called 'Performance-Based Design (PBD)' approach in fire safety engineering. However, they also noted how structural fire engineering is still heavily based on the concept of 'fire resistance' and related data tests that often produce non-significant results.

The adoption of different and fresh perspectives may then be desirable. To this end, we can leverage ongoing research activities and project applications which have led to the production of guidelines and technical documents.

We consider the following issues are definitely worth a closer look: (1) the criteria for defining generalized and localized fire scenarios and specific fire models for analyzing the behavior of structures in fire; (2) the choice of significant substructures representative of the overall structural behavior, including the effect of constrained thermal expansions; (3) the identification of simple models to check the results of advanced non-linear modelling of structures in fire; (4) the criteria for designing structures with adequate structural robustness when catching fire.

However, the passive protection systems of steel structures (e.g. plasters, slabs, intumescent paints, etc.) should also be assessed within a PBD approach and not just as part of a prescriptive approach. This is because an optimal solution could be obtained by combining the results of advanced structural analysis with an appropriate selection and application of passive protection on the structural elements most often involved in the fire. We note that further theoretical and experimental characterization of the thermal properties of protective materials is required, in particular their reactive protection (e.g. intumescent paint). Indeed, thermo-mechanical properties identified as a result of standard tests could even be non-significant and/or negligible when using a PBD approach.

We believe that the integration of (1) fire science, (2) design methodologies for a safe and sustainable environment and, (3) engineering practice is possible if there

\footnotetext{
* Correspondence should be addressed to: Antonio Bilotta, E-mail: antonio.bilotta@unina.it
} 
is more awareness of the need to understand the genesis of problems - such as low resistance to fire and high repairing cost - and possible ways for preventing their uncontrolled development.

While past experiences represent an excellent starting point a change of pace is required. It is now time for the international scientific research community to initiate conversations and stimulate debate with representatives of professionals, associations, industry, institutions, and private companies.

The academic world can be at the forefront of this process through the continuous collection and systematic dissemination of the most advanced results of experimental studies - especially those conducted not only to demonstrate the achievement of the prescriptive regulatory requirement, but also to examine the physical and mechanical reasons for which an element, be it structural or not, can be considered more resistant and/or resilient to a fire in a building.

With this in mind Meloni et al. [1] worked on temperature path reconstruction for reinforced concrete and other materials under fire. They present the results of an experimental investigation on reinforced concrete, cement pastes, and mortars exposed to fire, with the aim to identify benchmarks relevant to reconstruct the thermal path. The authors noted how the absence of normative standards represented a stimulus for the development of experimental work in an innovative and reasoned manner.

Similarly, two papers have considered the development of more sustainable (i.e. recycled) materials resistant to fire. Pliya et al. [2] performed several tests on highstrength concrete (HSC) containing recycled coarse aggregate (RCA), as a partial replacement of natural coarse aggregate. In doing so, they considered parameters such as initial moisture content, ductility, heating rate, and preloading. Displacement measurements were obtained with the non-contact optical technique of digital image correlation (DIC). A scanning electron microscope (SEM) was used to identify the fractured surfaces of the RCA concrete. The study shows that an increased replacement ratio may contribute to reducing the risk of explosive spalling in high-strength concrete.

Figueiredo et al. [3] studied the effects of recycled steel and polymer fibres on explosive spalling of concrete in fire. High-performance concrete, increasingly used in tunnels and other infrastructure, is susceptible to explosive fire-induced spalling. Modern guidelines, then, recommend the use of small quantities of polypropylene fibres in the concrete mix to mitigate this problem. The experimental study investigated the effect of cleaned recycled fibres extracted from end-of-life tyres, showing that such fibres could successfully be used as an alternative to polypropylene. As such, these represent a safe and sustainable fire spalling mitigation solution.

Two more papers show that existing test methods are incomplete and not always applicable. Buch and Sharma [4] studied the fire resistance of eccentrically loaded reinforced concrete (RC) columns. The effect influence of reinforcement detailing on fire resistance of RC columns is known, but it is not supported by evidence of the relative impact on spalling and fire resistance when other parameters change, e.g. material, geometric, and loading variations. This is particularly an issue under combined normal force bending moment as experimental results indicate that the increase in load eccentricity increases the amount of spalling 
leading to decrease in fire resistance. The authors show that the existing methods are not applicable to columns with variable detailing under eccentric loading conditions.

Brunkhorst et al. [5] show a series of large-scale fire tests conducted to investigate various effects on the partial connection theory, on the composite loadbearing effect, and on the composite joint in case of fire. This work provides a useful description of the relevant methodology, including setup and sequencing of the tests that were undertaken.

Overall, the papers in this special section provide us with a not yet exhaustive, but variegated, picture of the recent research based on fire experiments. All papers include applications in the field and should be of interest to both academics and practitioners.

The Editors are grateful to all the authors and to the many reviewers who made this special section possible. Although it was not possible to include all submitted manuscripts, the editors hope that all authors found the feedback helpful for their future work. The Editors would also like to take this opportunity to thank Professor Guillermo Rein, Editor-in-Chief of the Fire Technology journal, for giving us the opportunity to work to this special section.

\section{References}

1. Meloni P, Mistretta F, Stochino F, Carcangiu G (2019) Thermal path reconstruction for reinforced concrete under fire. Fire Technol . https://doi.org/10.1007/s10694-019-00835-7

2. Pliya P, Cree D, Hajiloo H, Beaucour A, Green M, Noumowe A (2019) High-strength concrete containing recycled coarse aggregate subjected to elevated temperatures. Fire Technol . https://doi.org/10.1007/s10694-019-00820-0

3. Figueiredo F, Huang S, Angelakopoulos H, Pilakoutas K, Burgess I (2019) Effects of recycled steel and polymer fibres on explosive fire spalling of concrete. Fire Technol . https://doi.org/10.1007/s10694-019-00817-9

4. Buch SH, Sharma UK (2019) Fire resistance of eccentrically loaded reinforced concrete columns. Fire Technol . https://doi.org/10.1007/s10694-019-00823-x

5. Brunkhorst S, Pfenning S, Zehfuß J, Mensinger M (2019) Influence of elevated temperatures on the composite joint of a composite beam in fire. Fire Technol . https://doi.org/ 10.1007/s10694-018-0800-5

Publisher's Note Springer Nature remains neutral with regard to jurisdictional claims in published maps and institutional affiliations. 